\title{
MRI of early appendicitis during pregnancy
}

\author{
Jinchun Yan, ${ }^{1}$ Raja Sabbagh, ${ }^{2}$ Albert Adu, ${ }^{2}$ Anthony Gilet ${ }^{3}$ \\ ${ }^{1}$ Department of Radiology, University of Washington Medical Center, Seattle, Washington, USA \\ ${ }^{2}$ Department of Surgery, Harlem Hospital Center, New York, New York, USA \\ ${ }^{3}$ Department of Radiology, Harlem Hospital Center, New York, New York, USA
}

Correspondence to Dr Jinchun Yan, optimisticyan@gmail.com

\section{DESCRIPTION}

Diagnosis of appendicitis during pregnancy can be challenging because of atypical clinical presentations such as abdominal pain, nausea and vomiting, which can also appear in normal pregnancy. According to the American College of Radiology appropriateness criteria, ultrasound of the right lower quadrant with graded compression is the most appropriate initial imaging test in suspected appendicitis in a pregnant patient, especially during the first and early second trimester. ${ }^{1}$ Ultrasound with graded compression technique, although the first line investigation modality for suspected appendicitis in pregnancy, depends on variability in operator skills and may result in equivocal or indeterminate findings. ${ }^{2}$ If ultrasound is
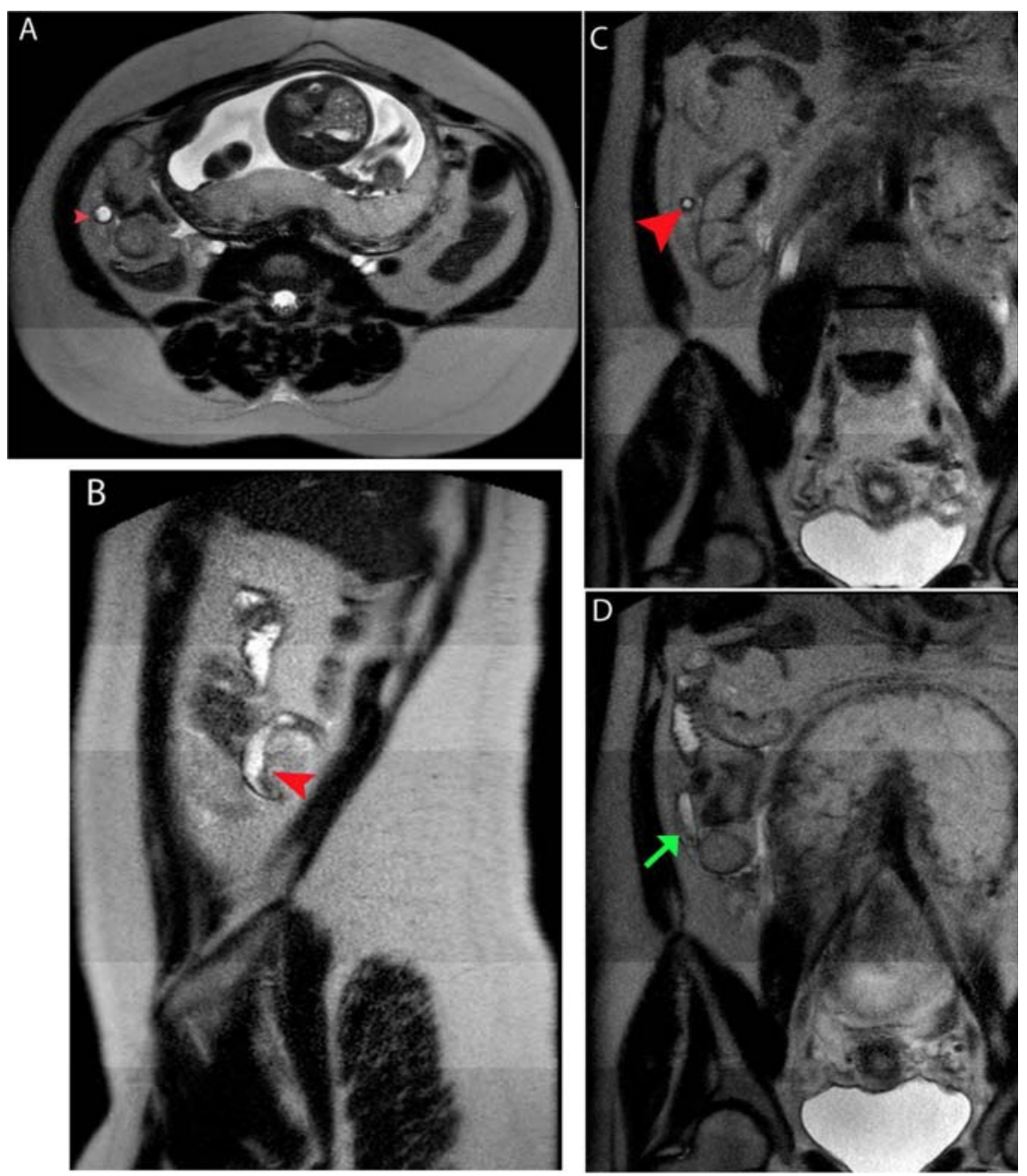

Figure 1 Early appendicitis in a 31 year-old G5P4 woman at 29 weeks gestational age who presented with acute abdominal pain, nausea and vomiting. She underwent a multiplanar multisequential non-contrast MRI of the abdomen/pelvis. Axial (A), sagittal reformatted (B), and coronal reformatted (C) T2-weighted images demonstrated a fluid-filled thick-walled appendix (red arrowhead) that was dilated up to $1.1 \mathrm{~cm}$ in the right lower quadrant lateral to the ceacum. There was mild periappendiceal inflammation, which was best shown at T2-weighted coronal reformatted images (D). There was no evidence for appendiceal rupture. The MR images suggested diagnosis of early appendicitis, which was confirmed at surgery and by pathology examination. 


\section{BMJ Case Reports}

non-diagnostic, MRI (if available), which lacks ionisation radiation, is more appropriate than CT for abdominal pain or clinically suspicious appendicitis in pregnancy. ${ }^{3} \mathrm{MRI}$, if available, has the additional advantage as it can frequently identify mimics of acute appendicitis, such as ectopic pregnancy, obstructing urinary tract calculi, pyelonephritis, adnexal and ovarian pathology, gallbladder disease, small bowel obstruction and other gastrointestinal conditions. In cases where ultrasound is non-diagnostic and MRI is unavailable or contraindicated (eg, patients with pacemakers or other MRI incompatible devices or materials), CT can be performed to avoid the morbidity of delayed diagnosis and intervention. In this case, after MR indication of early appendicitis, and considering that appendicitis can quickly progress to rupture with associated high fetal death rate and life-threatening complications during pregnancy, an immediate open appendectomy was performed. OR findings include a dilated and inflamed appendix (from tip to middle), with the appendix lumen filled by thick slime of mucus blockade. Subsequent pathology examination also confirmed the $\mathrm{MR}$ interpretation and $\mathrm{OR}$ findings of appendicitis. Patient tolerated the procedure well and was discharged postoperative day 5 in a stable condition with well being of herself and fetus (figure 1).

\section{Learning points}

According to the American College of Radiology appropriateness criteria, ultrasound of the right lower quadrant with graded compression is the most appropriate initial imaging test in suspected appendicitis in a pregnant patient, especially during the first and early second trimester. If ultrasound is non-diagnostic, MRI (if available), which lacks ionisation radiation, is more appropriate than CT for abdominal pain or clinically suspicious appendicitis in pregnancy.

- For acute appendicitis during pregnancy, appropriate surgical intervention is potentially life-saving. It can significantly decrease fetal morbidity and mortality and can prevent life-threatening complications.

- MRI, if available, has the additional advantage as it can frequently identify mimics of acute appendicitis in pregnant patients, such as obstructing urinary tract calculi, pyelonephritis, adnexal and ovarian pathology, gallbladder disease, small bowel obstruction and other Gl conditions. Early diagnosis and early intervention can avoid the morbidity associated with delayed diagnosis.

\section{Competing interests None.}

Patient consent Obtained.

\section{REFERENCES}

1. Rosen MP, Ding A, Blake MA, et al. ACR Appropriateness Criteria ${ }^{\circledR}$, Right lower quadrant pain — suspected appendicitis, version 2010. http://www.acr. org/ /media/7425A3E08975451EAB571A316DB4CA1B.pdf laccessed on 18 Aug 2012).

2. Wieseler KM, Bhargava $P$, Kanal KM, et al. Imaging in pregnant patients: examination appropriateness. Radiographics 2010;30:1215-29.

3. Singh A, Danrad R, Hahn PF, et al. MR imaging of the acute abdomen and pelvis: acute appendicitis and beyond. Radiographics 2007;27:1419-31.

This pdf has been created automatically from the final edited text and images.

Copyright 2012 BMJ Publishing Group. All rights reserved. For permission to reuse any of this content visit

http://group.bmj.com/group/rights-licensing/permissions.

BMJ Case Report Fellows may re-use this article for personal use and teaching without any further permission.

Please cite this article as follows (you will need to access the article online to obtain the date of publication).

Yan J, Sabbagh R, Adu A, Gilet A. MRI of early appendicitis during pregnancy. BMJ Case Reports 2012;10.1136/bcr-2012-006878, Published XXX

Become a Fellow of BMJ Case Reports today and you can:

- Submit as many cases as you like

- Enjoy fast sympathetic peer review and rapid publication of accepted articles

- Access all the published articles

- Re-use any of the published material for personal use and teaching without further permission

For information on Institutional Fellowships contact consortiasales@bmjgroup.com

Visit casereports.bmj.com for more articles like this and to become a Fellow 